BLS 34, No 1 2008. DOI: http://dx.doi.org/10.3765/bls.v34i1.3562

(published by the Berkeley Linguistics Society and the Linguistic Society of America)

\title{
Backwards Ellipsis is Right Node Raising ${ }^{1}$
}

\author{
SEUNGWAN HA \\ Korea University
}

\section{Backwards Ellipsis}

Natural language allows some part of utterance to be unpronounced when the part can be considered as redundant or as the given information. This nonpronunciation is called ellipsis, and ellipsis has been an intriguing research topic in syntax since the late sixties, as shown in papers such as Ross (1967).

\subsection{Forward vs. Backwards ellipsis}

Ellipsis can be divided into two different kinds with respect to the direction of ellipsis - forward and backwards ellipsis. Previous literature has mainly focused on forward ellipsis where the part subject to be ellipsis follows its antecedent in the previous utterance. ${ }^{2}$ Let us consider examples in $(1 \mathrm{a}-\mathrm{b})$. The VP is elided in the second conjunct in (1a), and the TP is in (1b), both finding its antecedent in the first conjunct.

a. John admires his teacher, but Bill doesn't $<$ admire his teacher $>$.

(Forward VP-ellipsis)

b. Mary told me she would buy a present for her daughter, but she didn't tell me what <she would buy for her daughter>.

(Forward sluicing)

There is another type of ellipsis, called backwards ellipsis, which this paper will be concerned with. Backwards ellipsis is similar to forward ellipsis in that there exists unpronounced material in the sentence. However, it differs from forward ellipsis since the antecedent follows the elided gap. Let us examples of backwards ellipsis in (2).

\footnotetext{
${ }^{1}$ I would like to thank Barbara Citko, Paul Hagstrom, Kyle Johnson, Jason Merchant for helpful comments and suggestions. All errors are my own.

${ }^{2}$ An Italicized phrase in an example indicates the antecedent of the elided phrase in this paper.
} 


\section{Seungwan Ha}

\section{a. Bill DOESN'T <>, but John DOES admire his teacher.}

(Backwards VP-ellipsis)

b. The journalists want to know IF $<>$, and WHEN the suspect will make a statement.

(Backwards sluicing)

(Giannakidou and Merchant 1998: 238)

Notice that the elided gap takes the VP in the second conjunct as an antecedent in (2a), so that the elided VP in the first conjunct is followed by its antecedent in the second conjunct. The same holds for backwards sluicing in (2b). The TP in the first conjunct is elided and its antecedent can be found in the second conjunct.

At the first glance, forward and backwards ellipsis seem to show a mirror image. The only difference appears to be a direction of ellipsis. Thus, let us make a null hypothesis in (3).

(3) Null hypothesis: backwards ellipsis is the same as forward ellipsis, but in the other direction.

a. The elided constituents (i.e. VP in (2a) and TP in (2b)) are followed by its antecedent.

b. Other than that, backwards ellipsis would show the same distribution with forward ellipsis.

\subsection{Backwards Anaphora Constraint}

However, it is not so much difficult to come up with examples where the hypothesis in (3) falls. Let us consider (4a-c).
a. Because Jeff did $<>$, his children had to go to church last Sunday.
b. *Jeff did $<>$ because his children had to go to church last Sunday.
c. *Jeff did $<>$, and his children went to church last Sunday, too.

While (4a) is grammatical, (4b-c) are not. Notice, however, that in all cases the elided gap is followed by its antecedent and our null hypothesis would predict all the examples in (4) to be grammatical, contrary to fact. This indicates that there is some difference between backwards ellipsis and forward ellipsis.

Langacker (1969) attempts to capture the differences in acceptability in (4). He proposed a constraint for the cases where the elided gap precedes its antecedent, which is called Backwards Anaphora Constraint (BAC). ${ }^{3}$

\footnotetext{
${ }^{3}$ Under Langacker's (1969) analysis, the BAC is more generally applied in (i):

(i) Backwards Anaphora Constraint:

An anaphora preceding its antecedent needs to be contained in a subordinate clause.
}

For example, the pronoun she precedes its antecedent Mary in (iia-b). However, only (iia) satisfies (i) because the backwards anaphora is in the subordinate clause. Therefore, the backwards 


\title{
Backwards Ellipsis is Right Node Raising
}

\author{
Backwards Anaphora Constraint \\ An ellipsis site cannot precede its antecedent when the ellipsis gap occurs \\ in the matrix clause \\ (Langacker 1969)
}

Under the BAC, it seems that grammaticality of VP-ellipsis in (4a-c) can be captured. (4a) is grammatical since the backwards ellipsis site is in the becauseclause. Examples in (4b-c) are ungrammatical since backwards ellipsis occurs in the matrix clause. Thus, $(4 \mathrm{~b}-\mathrm{c})$ constitute a violation of the BAC.

\section{Puzzles}

There is a significant problem for the BAC. The BAC incorrectly predicts both (1b) and (2b) to be ungrammatical, which are repeated in (6a-b).

a. Bill DIDN'T $<>$, but Sally already HAD called 911.

b. The journalists want to know IF $<>$, and (the police wondered) WHEN the suspect will make a statement.

Notice that the ellipsis gap is in the matrix clause. However, the gap can precede its antecedent. According to the definition in (5), this is the environment where the backwards anaphora should be blocked. Contrary to prediction, (6a-b) are grammatical.

It is interesting to note that the backwards ellipsis seems to be always accompanied by contrastive focus on the pre-elided constituent. The polarity on the auxiliary didn't is different from the one in had in the second conjunct in (6a), and the complementizer if in the first conjunct is contrastively compared with the wh-word when in the second conjunct. If there is no focus on the constituent, the grammaticality is significantly degraded. Consider (7a-b) which are minimally different from (6a-b).

a. $*$ Bill did $<>$, and Sally called 911 , too.

b. *The journalists have already concluded who $<>$, but the police still investigates who the suspect killed the other night.

In (7a-b), contrastive focus cannot be assigned on the auxiliary and the wh-word because polarity is the same and the same $w h$-word is used between the conjuncts, respectively. This indicates that contrastive focus has something to do with backwards anaphora, but this requirement does not have to be held in forward ellipsis. Under the Backwards Anaphora Constraint, however, it is not clear why contrastive focus matters in backwards ellipsis, but not in forward ellipsis.

anaphora is allowed. Consider (iib). The anaphora is in the main clause while its antecedent is in the subordinate clause. This violates the condition in (i), so that (iib) is ungrammatical.

(ii) a. Because she $_{i}$ needed to start early next morning, Mary ${ }_{i}$ went to bed on $9 \mathrm{pm}$.

b. ${ }^{*} \mathrm{She}_{i}$ went to bed on $9 \mathrm{pm}$ because Mary ${ }_{i}$ needed to start early next morning. 


\section{Seungwan Ha}

To summarize so far, we have observed Backwards ellipsis is not just a variant of ellipsis. It does not seem to be a matter of directionality of deletion. Instead, backwards ellipsis seems to be closely related with contrastive focus. Furthermore, the previous account, based on the BAC, undergenerates. The examples above are not constrained by the $\mathrm{BAC}$, because if they were, the examples in (6) would be equally ungrammatical, contrary to fact. In section 3, I will propose a new analysis for backwards ellipsis - an account based on the ellipsis analysis of Right Node Raising.

\section{Proposal}

I propose that backwards ellipsis is Right Node Raising (RNR): the examples in (6a-b) must be explained by a theory of RNR. There are three kinds of analyses for RNR available in previous literature: movement, multiple-dominance, and ellipsis (Ross 1967, Postal 1974, 1998, Hudson 1976, Wexler and Culicover 1980, McCawley 1982, Swingle 1993, Wilder 1997, 1999, Hartmann 2000, Sabbagh 2003, 2007, Abels 2004, An 2007, Ha 2007, among others). Since the main purpose of this paper is not to discuss the analyses of RNR, I will not introduce specifics of each analysis. For the details, readers may refer to Ha (2007).

In section 3.1, I will directly move on to an introduction of the deletion account of RNR, which this paper will be based on.

\subsection{A deletion account of RNR}

In this paper, we assume that RNR is a PF-deletion phenomenon (Wexler and Culicover 1980, Hartmann 2000, Abels 2004, An 2007, Ha 2007, among others). The RNR target does not undergo rightward movement, but stay in-situ in syntax. At PF, The target in the first conjunct is unpronounced, so that we cannot hear it. There are several versions of the deletion accounts in literature (e.g. Strict Phonological Deletion, ellipsis, etc.). Here, we will follow a proposal by Ha (2007) that there exists an elliptical feature for ellipsis and RNR (cf. Merchant 2001), and the sister constituent of the feature is licensed to be elided at PF.

\subsubsection{Merchant's e-GIVENness}

Merchant $(2001,2006)$ argues that an elliptical feature (henceforth, E) enters the derivation in a certain functional category when ellipsis occurs in a sentence. For example, the $\mathrm{C}$ head may bear an $\mathrm{E}$ feature, so that its sister constituent TP is elided at PF. This is how sluicing is derived. The $v$ head may bear an E feature. If so, VP-ellipsis is derived.

The $\mathrm{E}$ features also impose interface conditions at PF and LF. First, the sister constituent of the E feature is forced to be unpronounced at PF, showing a PFdeletion effect. Second, the elided constituent and its antecedent must be semantically identical at LF. As an LF condition of the E feature, Merchant proposes e-GIVENness conditions which are satisfied when the elided constituent and its antecedent mutually entail each other, modulo $\exists$-type shifting. The definition is provided in (8). 


\section{Backwards Ellipsis is Right Node Raising}

\section{e-GIVEN}

An expression $E$ counts as e-given iff $E$ has a salient antecedent $A$ and, modulo $\exists$-type shifting,

(i) A entails F-clo (E), and

(ii) E entails F-clo (A).

(Merchant 2001: 26)

Let us take an example in (9). This is an example of sluicing. The sentence bears an $\mathrm{E}$ feature in the $\mathrm{C}$ head in the second conjunct, so that the embedded $\mathrm{TP}$ is subject to be elided at PF if the e-GIVENness condition is satisfied.

$$
\begin{aligned}
& \text { Jonathan was talking to someone, but I don't know who } \mathrm{C}[\mathrm{E}]<\text { he was } \\
& \text { talking to } \mathrm{t}>\text {. } \\
& \text { a. } \mathrm{TP}_{\mathrm{A}}=\exists \mathrm{x}[\text { Jonathan was talking to } \mathrm{x}] \\
& \text { b. } \mathrm{TP}_{\mathrm{E}}=\exists \mathrm{x}[\text { Jonathan was talking to } \mathrm{x}] \\
& \text { c. } \mathrm{F}-\mathrm{clo}(\mathrm{A})=\mathrm{F} \text {-clo }(\mathrm{E})=\exists \mathrm{x}[\text { Jonathan was talking to } \mathrm{x}]
\end{aligned}
$$

To see whether the TP is e-GIVEN, we will need to consider which phrase is its antecedent. The antecedent can be found in the first conjunct. By existential closure of the indefinite, the antecedent yields (9a). The TP has a $w$-variable in the second conjunct, which must be existentially closed, as shown in (9b). Now, the conditions in (8) include any focused constituent turns into a variable which must also be existentially closed (i.e. F-closure). Since there is no focused constituent in either the antecedent or the elided phrase, F-clo (A) and F-clo (E) yield the same semantic formula in $(9 \mathrm{c}) . \mathrm{TP}_{\mathrm{A}}$ entails $\mathrm{F}$-clo $(\mathrm{E})$ and $\mathrm{TP}_{\mathrm{E}}$ entails $\mathrm{F}$ clo (A), which satisfies e-GIVENness in (8). Therefore, the embedded TP in the second conjunct is e-GIVEN, so that it is licensed to be unpronounced at PF.

\subsubsection{The $\mathbf{E}_{\mathrm{RNR}}$ analysis of $\mathrm{RNR}$}

I argue that an E feature must be employed in RNR (Ha 2007), and the E feature licensing RNR (henceforth, the $\mathrm{E}_{\mathrm{RNR}}$ feature) is a variant of Merchant's $\mathrm{E}$ features. It is similar with the E features licensing VP-ellipsis and sluicing since the eGIVENness condition must be satisfied between the RNRed constituent and its antecedent, and the sister of the $\mathrm{E}_{\mathrm{RNR}}$ feature is unpronounced at $\mathrm{PF}$. However, the $E_{\mathrm{RNR}}$ feature is different from the other elliptical features, in that unlike the other $\mathrm{E}$ features, the $\mathrm{E}_{\mathrm{RNR}}$ feature does not link to any particular functional head. Rather, it enters the derivation with the contrastively focused pre-RNR constituent.

We have already observed in section 2 that contrastive focus is crucial for RNR, and the contrastive focus prior to the RNR target in each conjunct makes it possible to delete the target at PF. Following Ha (2007), I assume that the $\mathrm{E}_{\mathrm{RNR}}$ feature enters the derivation with a contrastively focused pre-RNR constituent in the first conjunct (Ha 2007, cf. Hartmann 2000). And nonpronunciation of the RNR target is licensed under semantic identity, in particular by e-GIVENness (Merchant 2001). The syntactic, phonological, and semantic requirements that the $\mathrm{E}_{\mathrm{RNR}}$ feature imposes for RNR are provided in (10). 


\section{Seungwan Ha}

(10) The $\mathrm{E}_{\mathrm{RNR}}$ feature (Ha 2007)

a. Syntax of $E_{R N R}$ : The $E_{R N R}$ feature enters the derivation with the contrastively focused pre-RNR constituent in the first conjunct.

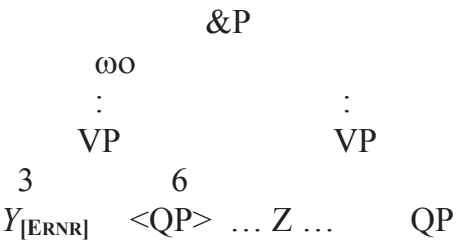

b. Phonology of $\mathrm{E}_{\mathrm{RNR}}$ : QP $\rightarrow \varnothing / \mathrm{E}_{\mathrm{RNR}}$

c. Semantics of $E_{\text {RNR }}$ : e-GIVENness must be observed in RNR.

i) $\mathrm{RNR} \rightarrow$ F-clo $(\mathrm{A})$

ii) $\mathrm{A} \rightarrow \mathrm{F}$-clo (RNR).

Let us consider an example in (11) to see how the $\mathrm{E}_{\mathrm{RNR}}$ analysis works. If our sentence makes use of a RNR construction, the numeration contains contrastively focused lexicons. I assume that contrastively focused lexicons enter the derivation with the $E_{\text {RNR }}$ feature. As shown in (11a), the contrastively focused verb LIKES bears the $\mathrm{E}_{\mathrm{RNR}}$ feature and enters the derivation. The sister constituent of the $\mathrm{E}_{\mathrm{RNR}}$ feature is determined to be the RNR target in syntax. Phases are spelled out and sent to PF for linearization cyclically (Fox and Pesetsky 2005, cf. Chomsky 2001). Linearization takes place and interface conditions, such as e-GIVENness, are considered, as in (11c-d).

(11) John LIKES $<$ the opera $>$, but MARY HATES - the opera.

a. Syntax: The $E_{R N R}$ feature enters the pre-RNR constituent in the first conjunct.

John LIKES $_{[\text {ERNR] }}<$ the opera $>$, but MARY HATES the opera.

b. Spellout: Linearization and check the interface conditions are satisfied.

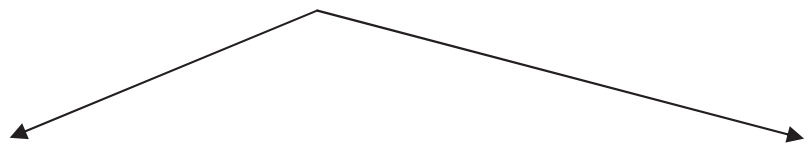

c. PF: Do not pronounce the sister of $\mathrm{E}_{\mathrm{RNR}}$

d. LF: Check e-GIVENness

When the sentence is linearized at the spellout, the linear order is determined by asymmetrical c-command relations between terminal nodes á la Kayne's (1994) Linear Correspondence Axiom. In each conjunct, the subject NP asymmetrically c-commands the verb, so that it precedes the verb. The verb asymmetrically ccommands the object DP, so that it precedes the DP. Within the DP, the 


\section{Backwards Ellipsis is Right Node Raising}

determiner precedes the NP. Assuming the binary branching analysis of coordination (Munn 1993), the first conjunct asymmetrically c-commands the second conjunct. Therefore, all the nodes inside the first conjunct precede nodes in the second conjunct. As a result, the linear order is determined as in (12).

$$
\begin{aligned}
& \text { PF-deletion of the opera: } \\
& \text { John }>\text { LIKES }>(\text { the }>\text { opera })_{\mathrm{E}}>\text { but }>\text { MARY }>\text { HATES }>\text { the opera }
\end{aligned}
$$

The RNR target the opera determined by syntax is marked with $\mathrm{E}$, and the pronunciation of the target is skipped at PF.

At LF, the computation system checks whether the RNR target is e-GIVEN. The RNR clause entails F-clo (A), as shown in (13a), and the antecedent clause entails F-clo (E), as shown in (13b). Therefore, the e-GIVENness condition is satisfied.

$$
\begin{aligned}
& \text { a. RNR } \rightarrow \text { F-clo (A): JOHN LIKES the opera } \rightarrow \exists x \exists R \text { [x R-ed the opera] } \\
& \text { b. A } \rightarrow \text { F-clo (RNR): MARY HATES the opera } \rightarrow \exists x \exists R \text { [x R-ed the } \\
& \text { opera] }
\end{aligned}
$$

All the interface conditions imposed by the $\mathrm{E}_{\mathrm{RNR}}$ feature are met, so (11) is a good RNR example. Let us see how our earlier examples can be explained under this $\mathrm{E}_{\mathrm{RNR}}$ analysis in the next section.

\subsection{Backwards ellipsis is RNR}

Let us compare (6a-b) with (7a-b), which are repeated in (14) and (15) respectively. In both examples, the elided gap appears in the first conjunct and their antecedent can be found in the second conjunct.

a. Bill DIDN'T $<$, but Sally already HAD called 911 .

b. The journalists want to know IF $<>$, and (the police wondered) WHEN the suspect will make a statement.

(15) a. *Bill did $<>$, and Sally called 911 , too.

b. *The journalists have already concluded who $<>$, but the police still investigates who the suspect killed the other night.

While contrastive focus is assigned on the auxiliaries and the wh-phrase in (14), it does not in (15). I propose that this is the key difference between (14) and (15). Following $\mathrm{Ha}$ (2007), the $\mathrm{E}_{\mathrm{RNR}}$ feature may enter the derivation on the constituents prior to the elliptical target in (14), but it is not the case in (15). Since there is no contrastive focus assigned on the pre-ellipsis target in $(15 \mathrm{a}-\mathrm{b})$, no $\mathrm{E}_{\mathrm{RNR}}$ feature can enter the derivation. Consequently, PF-deletion cannot be motivated in (15). 


\section{Seungwan Ha}

It is crucial to notice that both (14) and (15) are not examples of VP-ellipsis and sluicing since the counterpart forward ellipsis of (15a-b) is perfectly grammatical, as shown in (16).

a. Sally called 911, and Bill did $<>$, too.

b. The police still investigates who the suspect killed the other night, but the journalists have already concluded who $<>$.

If they were ellipsis and followed the same licensing conditions with forward ellipsis, there would be no way to explain why (15) is ungrammatical while its counterpart (16) is grammatical. In other words, if the same E features for VPellipsis and sluicing entered the derivation in (15a-b), ellipsis would be licensed on the grounds that the e-GIVENness condition is satisfied.

This indicates that a different $\mathrm{E}$ feature - in fact, a different type of $\mathrm{E}$ feature enters the derivation and licenses the PF-deletion in (14). It is different from the other $\mathrm{E}$ features because it does not enter in a functional head but enters with a contrastively focused lexicon. The feature is argued to be the $\mathrm{E}_{\mathrm{RNR}}$ feature and the deletion licensed by the feature is called RNR.

Now, let us consider the examples in more detail. Let us first take the grammatical examples in (14). Note that the auxiliaries are contrastively focused in (14a): didn't in the first and had in the second conjunct, and the $\mathrm{E}_{\mathrm{RNR}}$ feature enters the derivation with didn't. We assume that there exists a VerumP in between TP and $v \mathrm{P}$, and the Verum head has a binary value of polarity: negative and affirmative focus, as shown in (17). ${ }^{4}$

$$
\begin{aligned}
& \text { Jeff [verumP DIDN'T }{ }_{[\text {ERNR] }}[\text { vp1 }<\text { eall 911>]] because Sally already [verumP } \\
& \text { HAD [vP2 called 911]]. }
\end{aligned}
$$

I argue that it is the Verum head that bears the $E_{R N R}$ feature and licenses the deletion of VP in the first conjunct. The semantic identity condition is satisfied since VP1 counts as e-GIVEN. This is so because VP1 and VP2 mutually entail each other, modulo $\exists$-type shifting, as shown in (18). Commonly assumed in ellipsis, morphological mismatches are ignored here (Merchant 2001).

$$
\mathrm{VP} 1 \leftrightarrow \mathrm{VP} 2=\exists \mathrm{x}[\mathrm{x} \text { call 911] } \leftrightarrow \mathrm{y}[\mathrm{y} \text { called } 911]
$$

Since the e-GIVENness condition is satisfied, the RNR target, which is the sister of the $\mathrm{E}_{\mathrm{RNR}}$ feature, can be unpronounced at $\mathrm{PF}$.

The same holds for (14b), repeated in (19). The complementizer if is compared by the $w h$-phrase who, so they are contrastively focused. Thus, the $\mathrm{E}_{\mathrm{RNR}}$ feature enters the derivation with the complementizer in the first conjunct. To see

\footnotetext{
${ }^{4}$ It is sometimes called PolarityP in literature (Culicover 1991).
} 


\section{Backwards Ellipsis is Right Node Raising}

if the semantic identity condition is met, we consider whether the TP1 the suspect will make a statement is e-GIVEN.

(19) The journalists want to know $\mathrm{IF}_{[\mathrm{ERNR}]}<[$ TP1 the suspect will make a statement]>, and the police wondered WHEN [TP2 the suspect will make a statement].

This is shown in (20). TP1 is e-GIVEN on the grounds that TP1 and TP2 mutually entail each other; that is, TP1 entails F-clo (TP2) and TP2 entails F-clo (TP1). Therefore, TP1 can be unpronounced at PF.

a. TP1 $=\exists \mathrm{t}$ [the suspect will make a statement (at t)]

b. $\mathrm{TP} 2=\exists \mathrm{t}$ [the suspect will make a statement at $\mathrm{t}]$

c. $\mathrm{F}$-clo $(\mathrm{TP} 1)=\mathrm{F}$-clo $(\mathrm{TP} 2)=\exists \mathrm{t}$ [the suspect will make a statement at $\mathrm{t}]$

Let us turn to why (7a-b), repeated in (21a-b), are not grammatical. Let us first take (21a). Given the assumption that the elision of VP in the matrix clause is due to RNR, what we need to show is that (21a) does not provide the necessary environment for licensing RNR. Since the auxiliary does not bear contrastive focus - i.e. the focus value of the Verum head is identically affirmative - the $E_{\mathrm{RNR}}$ feature cannot enter the derivation, as shown in (21a). Thus, RNR is not possible, and PF-deletion of the target is not licensed.

a. *Jeff [verumP $\operatorname{did}_{[ø]}$ [affirmative focus] <ealled 911>] and Sally [verumP [affirmative focus] called 911], too.

b. *The journalists have already concluded who ${ }_{[ø]}<$ the suspect killed the other night $>$, but the police still investigates who the suspect killed the other night.

Similarly, since the $w h$-word in each conjunct is identical, no contrastive focus is assigned, which in turns means no $\mathrm{E}_{\mathrm{RNR}}$ feature enters the derivation. Therefore, PF-deletion of the TP in (21b) is not licensed.

An interesting issue worth mentioning here in backwards sluicing (i.e. RNR of the embedded TP in the first conjunct) is that backwards sluicing is impossible with argument wh-phrases (Giannakidou and Merchant 1998). Let us consider (22).

(22) a. *Lucy was wondering whether and who might come to her party.

b. *The reporters asked if and who the FBI had arrested.

(Giannakidou and Merchant 1998: 239)

(22a-b) are different from the previous backwards sluicing cases since the whword, contrastively compared with the complementizer, is an argument. And the question is why this matters. Suppose that a contrastive focus is assigned on if, 


\section{Seungwan Ha}

hence bearing the $\mathrm{E}_{\mathrm{RNR}}$ feature. The computation of e-GIVENness for (22b) would look like (23a-c).

*The reporters asked $\mathrm{IF}_{[\mathrm{ERNR}]}<$ the $\mathrm{FBI}$ had arrested anyone $>$ and $\mathrm{WHO}$ the FBI had arrested t.

a. $\mathrm{RNR}=\exists \mathrm{x}$ [The FBI had arrested $\mathrm{x}]$.

b. $A=\exists x$ [The FBI had arrested $x]$.

c. $\mathrm{F}$-clo $(\mathrm{A})=\mathrm{F}$-clo $(\mathrm{RNR})=\exists \mathrm{x}$ [The FBI had arrested $\mathrm{x}]$

Since mutual entailment relationship is established between the conjuncts, eGIVENness is satisfied; thus, RNR is predicted to be licensed in (23), contrary to fact.

Note that similar version of forward sluicing is licensed in (24). This suggests that the problem does not lie on e-GIVENness but on the entrance of the $E_{\text {RNR }}$ feature in syntax. For some reason, if with argument $w h$-phrases cannot be contrastively focused, while if with adjunct wh-phrases can be. However, at this point, I do not know why this is so. This will be left for future investigation.

(24) The CNN reporters asked if the FBI had arrested anyone, and the FOX news already claimed to know who <the FBI had arrested anyone $>$.

There is another possible version of backwards sluicing, which has not been introduced in Giannakidou and Merchant (1998). Let us take (25a-b). Compared with the previous cases, notice that there is no $w h$-phrase in the antecedent clause here. The second conjunct contains an indefinite while wh-movement occurs in the first conjunct. Now, a question arises as to whether they are also RNR examples. The issue here is whether the $\mathrm{E}_{\mathrm{RNR}}$ feature could enter the derivation with the wh-constituent in (25)?

a. I don't know which $\mathrm{ONE}_{[\mathrm{ERNR}]}($ ?) $<$ Mary bought $\mathrm{t}$ for the department $>$, but Mary told us she bought a new espresso machine for the department.

b. I don't remember WHO [ERNR] (?) < visited our class yesterday>, but a professor from the psychology department visited our class yesterday.

It is clear that a certain type of focus needs to be assigned on the wh-phrase, given the common assumption that all the $w h$-phrases bear a focus from one way or the other. However, it is not clear if the focus on the $w h$-word is a contrastive focus. One can imagine that the $w h$-word which incurs sluicing bears a contrastive focus in the sense that the $w h$-movement in the second conjunct marks a different scope, compared with the indefinite in the second conjunct (cf. Gengel 2006). If this is true, then the $\mathrm{E}_{\mathrm{RNR}}$ feature can enter with the wh-word, and RNR would be licensed. However, this also requires further investigations. 


\section{Backwards Ellipsis is Right Node Raising}

\subsection{VP-ellipsis}

Finally, let us consider (4a), repeated in (26). The elided gap precedes its antecedent. Therefore, from what we have claimed so far in this paper, this must be the case of RNR. However, no contrastive focus is involved here because the polarity is the same between the clauses, which in turn means that no $\mathrm{E}_{\mathrm{RNR}}$ feature can enter in the because-clause. Nevertheless, PF-deletion of the VP in the because-clause seems to be possible. How could that be?

$$
\text { Because Jeff } \operatorname{did}_{[\varnothing]}<>\text {, his children had to go to church last Sunday. }
$$

Before we try to answer the question, let us first compare (26) with the previous case in (4b), repeated in (27). The clear difference is that the ellipsis clause is in the adjunct clause in (26), but it is in the matrix clause in (27).

$$
\text { *Jeff } \operatorname{did}<>\text { because his children had to go to church last Sunday. }
$$

We assume that the adverbial clause is base-generated to $v \mathrm{P}$ as an adjunct, where VP-ellipsis is licensed under semantic identity with the matrix VP, as shown in (28).

(28) His children had to go to church last Sunday [CP because Jeff did $v_{[\mathrm{E}]}<\mathrm{g} \theta$ to chureh last Sunday>].

The surface form is derived by dislocation of the adjunct clause, as shown in (29). This suggests that (26) is a case of normal VP-ellipsis, while (27) is an example of RNR.

(29) [CP Because Jeff did $v_{[\mathrm{E}]}<\mathrm{g} 0$ - church last Sunday $>$, his children had to go to church last Sunday.

\section{Conclusion}

In this paper, we observed examples of ellipsis where the antecedent follows the elided gap, and attempted to characterize the nature of the deletion. We concluded that what looks like backwards ellipsis is, in fact, RNR, on the grounds that forward ellipsis accounts fail to account for the examples of backwards ellipsis and there is a substantial similarity between backwards ellipsis and RNR. We applied the $\mathrm{E}_{\mathrm{RNR}}$ analysis, proposed by $\mathrm{Ha}$ (2007), to backwards ellipsis cases, and found out they fit in Ha's analysis. Therefore, we conclude that backwards ellipsis is not a type of ellipsis, but it is a RNR construction.

\section{References}

Abels, Klaus. 2004. Right Node Raising: Ellipsis or ATB movement? In Keir Moulton, and Matthew Wolf (eds.), Proceedings of the $34^{\text {th }}$ North East 


\section{Seungwan Ha}

Linguistics Society, 44-59. Amherst: Graduate Linguistics Student Association Publications, University of Massachusetts.

Chomsky, Noam. 2001. Derivation by phase. In Michael Kenstowicz, ed., Ken Hale. A Life in Language, 1-52. Cambridge, MA: Massachusetts Institute of Technology Press.

Fox, Danny and David Pesetsky. 2005. Cyclic linearization of syntactic structure. Theoretical Linguistics 31: 1-45.

Giannakidou, Anastasia, and Jason Merchant. 1998. Reverse sluicing in English and Greek. Linguistic Review 15: 295-333.

Ha, Seungwan. 2007. Ellipsis, Right Node Raising, and Across-the-Board Constructions. Ph.D. diss, Boston University.

Hartmann, Katharina. 2000. Right Node Raising and Gapping: Interface Conditions on Prosodic Deletion. Amsterdam: John Benjamins.

Kayne, Richard. 1994. The Antisymmetry of Syntax. Cambridge, MA: Massachusetts Institute of Technology Press.

Langacker, Ronald. 1969. On pronominalization and the chain of command. In David A. Reibel and Sanford A. Schane (eds.) Modern Studies in English. New Jersey: Prentice-Hall, 160-186.

Merchant, Jason. 2001. The Syntax of Silence. Oxford: Oxford University Press.

Munn, Alan. 1993. Topics in the syntax and semantics of coordinate structures. Ph.D. diss, University of Maryland, College Park.

Postal, Paul. 1998. Three Investigations of Extraction. Cambridge, MA: The Massachusetts Institute of Technology Press.

Ross, John. 1967. Constraints on variables in syntax. Ph.D. diss, Massachusetts Institute of Technology.

Sabbagh, Joseph. 2007. Ordering and linearizing rightward movement. Natural Language and Linguistic Theory 25:349-401.

Swingle, Kari. 1993. The role of prosody in Right Node Raising. Ms., University of California, Santa Cruz.

Wexler, Ken, and Peter Culicover. 1980. Formal Principles of Language Acquisition. Cambridge, MA: Massachusetts Institute of Technology Press.

Wilder, Chris. 1999. Right Node Raising and the LCA. In Proceedings of the 18th West Coast Conference in Formal Linguistics, 586-598. Somerville, MA: Cascadilla Press.

Seungwan Ha

Research Institute of Language and Information

Korea University

5-ka Anam-dong, Sungbuk-ku

Seoul 136-701

South Korea

seungwan@korea.ac.kr 